\title{
Activation of homologous recombination DNA repair in human skin fibroblasts continuously exposed to $\mathrm{X}$-ray radiation
}

\author{
Andreyan N. Osipov ${ }^{1,2,3,4}$, Anna Grekhova ${ }^{1,5}$, Margarita Pustovalova ${ }^{1,2}$, \\ Ivan V. Ozerov ${ }^{1}$, Petr Eremin ${ }^{1}$, Natalia Vorobyeva ${ }^{1,3}$, Natalia Lazareva $^{1}$, Andrey \\ Pulin $^{1}$, Alex Zhavoronkov ${ }^{4,6,7}$, Sergey Roumiantsev ${ }^{3,4,8}$, Dmitry Klokov ${ }^{9}$, Ilya Eremin ${ }^{1}$ \\ ${ }^{1}$ State Research Center - Burnasyan Federal Medical Biophysical Center of Federal Medical Biological Agency (SRC-FMBC), \\ Moscow 123098, Russia \\ ${ }^{2}$ Semenov Institute of Chemical Physics, Russian Academy of Sciences, Moscow 119991, Russia \\ ${ }^{3}$ Dmitry Rogachev Federal Research Center of Pediatric Hematology, Oncology and Immunology, Moscow 117997, Russia \\ ${ }^{4}$ Moscow Institute of Physics and Technology, Dolgoprudny, Moscow Region 141700, Russia \\ ${ }^{5}$ Emanuel Institute for Biochemical Physics, Russian Academy of Sciences, Moscow 119991, Russia \\ ${ }^{6}$ Insilico Medicine, Inc, ETC, Johns Hopkins University, Baltimore, MD 21218, USA \\ ${ }^{7}$ The Biogerontology Research Foundation, BGRF, London W1J 5NE, UK \\ ${ }^{8}$ N.I. Pirogov Russian National Research Medical University, Moscow 117997, Russia \\ ${ }^{9}$ Canadian Nuclear Laboratories, Chalk River, ON K0J1P0, Canada \\ Correspondence to: \\ Andreyan N. Osipov, e-mail: andreyan.osipov@gmail.com \\ Keywords: DNA DSB repair, homologous recombination, human fibroblasts, $X$-rays, continuous irradiation
}

Received: April 08, $2015 \quad$ Accepted: July 31, $2015 \quad$ Published: August 13, 2015

\section{ABSTRACT}

Molecular and cellular responses to protracted ionizing radiation exposures are poorly understood. Using immunof luorescence microscopy, we studied the kinetics of DNA repair foci formation in normal human fibroblasts exposed to $X$-rays at a dose rate of $4.5 \mathrm{mGy} / \mathrm{min}$ for up to $6 \mathrm{~h}$. We showed that both the number of yH2AX foci and their integral fluorescence intensity grew linearly with time of irradiation up to $2 \mathrm{~h}$. A plateau was observed between 2 and $6 \mathrm{~h}$ of exposure, indicating a state of balance between formation and repair of DNA double-strand breaks. In contrast, the number and intensity of foci formed by homologous recombination protein RAD51 demonstrated a continuous increase during $6 \mathrm{~h}$ of irradiation. We further showed that the enhancement of the homologous recombination repair was not due to redistribution of cell cycle phases. Our results indicate that continuous irradiation of normal human cells triggers DNA repair responses that are different from those elicited after acute irradiation. The observed activation of the error-free homologous recombination DNA double-strand break repair pathway suggests compensatory adaptive mechanisms that may help alleviate long-term biological consequences and could potentially be utilized both in radiation protection and medical practices.

\section{INTRODUCTION}

Ionizing radiation exposure leads to a variety of DNA lesions, but the fate of the cell is largely determined by DNA double-strand breaks. These potentially lethal lesions are thought to be triggers of cellular responses to irradiation [1-3]. While the absolute number of DNA double-strand breaks per radiation dose unit is relatively low, estimated to be $20-40$ breaks per cell per Gy $[4,5]$, the repair of DNA double-strand breaks is a slow and complex process involving tens of various proteins, spanning large areas of chromatin and affecting its conformation [6]. Misrepair or failure to repair a DNA double-strand break may lead to cytogenetic abnormalities, cell death, inactivation of tumor suppressor genes or activation of oncogenes [7-9].

Formation and repair of DNA double-strand breaks upon acute radiation exposures is relatively well 
characterized (e.g. see a review by Thompson [6]). In general, DNA double-strand breaks can be repaired by one of the two major mechanisms: non-homologous endjoining (NHEJ) or homologous recombination (HR). NHEJ repair, involved in an estimated $\sim 80 \%$ of DNA double-strand breaks [6], is cell cycle independent and fast, taking approximately 30 minutes to complete [10]. However, NHEJ is error-prone and can lead to various genetic abnormalities [11]. In contrast, HR repair is errorfree and slow $(>7 \mathrm{~h}[10])$ and requires a sister chromatid as a template for DNA synthesis in the vicinity of a break on the damaged chromatid. Therefore, this pathway is active mainly in cells in S and G2 cell cycle phases [12]. HR is also specifically involved in the repair of collapsed replication forks [13]. It is, therefore, important to know relative contributions of the two DNA double-strand break repair pathways in order to better predict or understand delayed consequences of exposure to radiation.

Although repair of radiation-induced DNA doublestrand breaks is well studied for acute irradiation, responses to DNA double-strand breaks produced by continuous or chronic exposures to ionizing radiation are not well characterized [14-17]. Yet, most of the time, human cells are exposed to ionizing radiation chronically at low doserates, and possible health consequences of such exposures are of great concern [18-20]. The challenges for such continuous irradiation studies include both technical ones related to irradiation facilities and difficulties in interpreting results. For example, one would need to account for i) two opposite but concurrent processes of accumulation and elimination of DNA damage during exposure, ii) cell cycle redistribution, and iii) cell proliferation during exposure, i.e. a dose is split between mother and daughter cells, etc.

Advances in understanding molecular mechanisms of DNA double-strand break repair provide powerful experimental tools. In particular, these include identification of individual proteins or protein posttranslational modifications that form complex dynamic structures in the vicinity of individual double-strand breaks. There may be thousands of copies of those molecules involved in processing of a single DNA double-strand break. Immunofluorescent labeling of such proteins makes possible microscopic visualization of the DNA repair structures as distinct spots or foci that typically correspond to individual DNA doublestrand breaks [21-23]. This allows for very accurate and sensitive indirect quantification of DNA double-strand breaks and their repair, thus facilitating examination of molecular mechanisms of the repair process. By far the most common marker of DNA double-strand breaks is phosphorylated histone $\mathrm{H} 2 \mathrm{AX}$, called $\gamma \mathrm{H} 2 \mathrm{AX}$ [24]. H2AX is phosphorylated by ATM, ATR or DNA-PK kinases in response to DNA double-strand break formation and signifies the recognition of a break [25]. To examine the involvement of HR in the repair process, foci formed by the HR core component, RAD51 protein, are typically measured [26-28].

Given the importance of DNA double-strand breaks and their processing for health outcomes and the lack of clear understanding of how cells respond to chronic irradiation, we sought to measure formation of DNA double-strand breaks and the rate of HR in human diploid fibroblasts upon continuous irradiation in this study. We quantified total number of DNA double-strand breaks using $\gamma \mathrm{H} 2 \mathrm{AX}$ foci and in parallel, evaluated the extent of HR repair by measuring RAD51 foci.

\section{RESULTS}

\section{Increase in number of $\gamma \mathrm{H} 2 \mathrm{AX}$ foci}

Primary cultures of diploid human fibroblasts were exposed to continuous $\mathrm{X}$-ray radiation at a dose-rate of $4.5 \mathrm{mGy} / \mathrm{min}$ under normal growth conditions for up to $6 \mathrm{~h}$. At various times from the exposure start, cells were fixed and immuno-fluorescently labelled for $\gamma \mathrm{H} 2 \mathrm{AX}$ and RAD51. Kinetics of $\gamma \mathrm{H} 2 \mathrm{AX}$ foci formation is shown in Figure 1A. An increase in the foci number was detected at the earliest time-point of $15 \mathrm{~min}$ from the start of exposure corresponding to a $67.5 \mathrm{mGy}$ cumulative dose. The number of $\gamma \mathrm{H} 2 \mathrm{AX}$ foci continued to increase linearly with exposure time for up to $2 \mathrm{~h}(540 \mathrm{mGy})$. The curve of $\gamma \mathrm{H} 2 \mathrm{AX}$ foci accumulation could be best fit with a linear function $\mathrm{y}=(2.24 \pm 0.48)+(50.41 \pm 1.72)$ $\mathrm{x}\left(R=0.998, p=0.0001, \mathrm{R}^{2}=0.996\right)$, where $\mathrm{y}$ is $\gamma \mathrm{H} 2 \mathrm{AX}$ foci/nucleus, $\mathrm{x}$ is dose in Gy. The number of $\gamma \mathrm{H} 2 \mathrm{AX}$ foci per Gy could be easily calculated from this relationship and was $50.41 \pm 1.72$.

Continuation of irradiation beyond $2 \mathrm{~h}$ did not result in a statistically significant increase in $\gamma \mathrm{H} 2 \mathrm{AX}$ foci (Figure 1A). Although, for 3 and $4 \mathrm{~h}$ time-points ( 0.81 and $1.08 \mathrm{~Gy}$, respectively) higher values of $\gamma \mathrm{H} 2 \mathrm{AX}$ foci were recorded compared with $2 \mathrm{~h}$, they were not significant and were followed by a slight decrease at 5 and $6 \mathrm{~h}$ (1.35 and $1.62 \mathrm{~Gy}$, respectively). Therefore, we observed a plateau at about 30 foci per cell that persisted from $2 \mathrm{~h}$ untill at least $6 \mathrm{~h}$ of exposure.

To verify that the plateau was not a methodological artefact, we generated a dose-response curve using acute irradiation (Figure 1B). Cells were exposed to $\mathrm{X}$-ray radiation at a dose rate of $400 \mathrm{mGy} / \mathrm{min}$ and fixed at $30 \mathrm{~min}$ post-irradiation when the maximum number of $\gamma \mathrm{H} 2 \mathrm{AX}$ foci is typically observed. A linear dose-response curve $(\mathrm{y}=(4.96 \pm 1.44)+(33.00 \pm 1.59)$ $\left.\mathrm{x}\left(\mathrm{R}=0.994, p=0.000001, \mathrm{R}^{2}=0.989\right)\right)$ in the entire range of doses used up to 1.5 Gy was observed with the number of $\gamma \mathrm{H} 2 \mathrm{AX}$ foci increasing up to 50 foci/cell, which is well above the $30 \mathrm{foci} /$ cell value observed for the continuous irradiation plateau. Thus, the lack of a dose-dependent increase in the number of $\gamma \mathrm{H} 2 \mathrm{AX}$ foci 

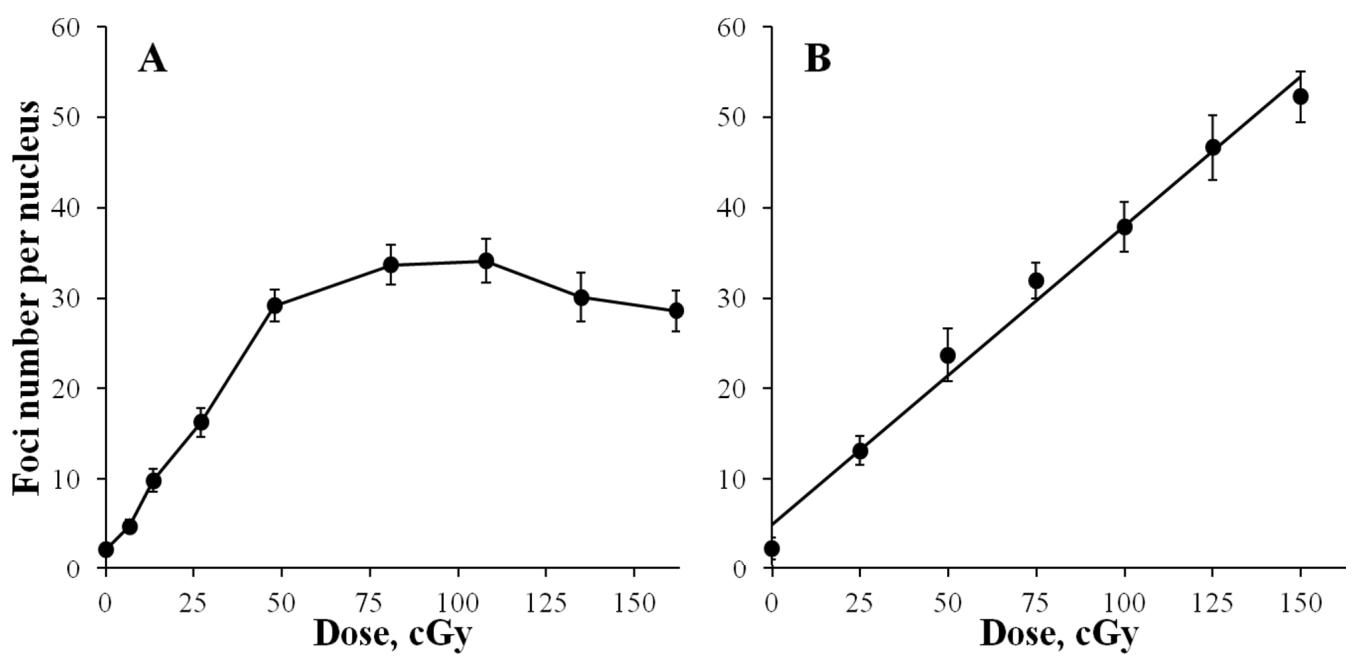

Figure 1: Formation of $\gamma \mathrm{H} 2 \mathrm{AX}$ foci in diploid normal human fibroblasts during continuous exposure to $\mathrm{X}$-ray radiation at a dose-rate of $4.5 \mathrm{mGy} / \mathrm{min} \mathrm{A}$. or $30 \mathrm{~min}$ after acute X-ray irradiation $\mathbf{B}$. $\gamma \mathrm{H} 2 \mathrm{AX}$ foci were quantified using immunofluorescence microscopy. Two hundred cells per data point were analyzed per experiment. Means calculated from three independent experiments \pm standard errors are shown.

registered between 2 and $6 \mathrm{~h}$ of continuous irradiation was not due to method limitations.

\section{Increase in integral $\gamma \mathrm{H} 2 \mathrm{AX}$ fluorescence intensity}

As the number of double-strand breaks grows with time of exposure, the probability of two individual breaks arising within close proximity and appearing as a single $\gamma \mathrm{H} 2 \mathrm{AX}$ focus increases. This may lead to underestimation of the real number of $\gamma \mathrm{H} 2 \mathrm{AX}$ foci and the appearance of the plateau on the curve that was observed between 2 and $6 \mathrm{~h}$ in Figure 1A. However, by measuring integral fluorescence intensity, as opposed to foci number, the contribution of this factor in the resulting kinetics of $\gamma \mathrm{H} 2 \mathrm{AX}$ foci accumulation may be examined. Results of such measurements are presented in Figure 2A. The initial phase of linear accumulation of integral $\gamma \mathrm{H} 2 \mathrm{AX}$ fluorescence with time (dose) up to $2 \mathrm{~h}$ was followed by slight decreases of fluorescence at $3,4,5$ and $6 \mathrm{~h}$ compared with that observed at $2 \mathrm{~h}$. As in the case of $\gamma \mathrm{H} 2 \mathrm{AX}$ foci number, the changes after $2 \mathrm{~h}$ were not statistically significant. We also plotted a doseresponse curve for acute irradiation for integral $\gamma \mathrm{H} 2 \mathrm{AX}$ fluorescence and found a linear relationship that spanned up to 370,000 fluorescence units, which substantially exceeds the value of 230,000 units at which the plateau was observed for continuous irradiation (Figure 1B). Thus, both quantification of foci number and measurement of integral fluorescence used in this study have a wide linear range that is sufficient for reliable analyses of chronically irradiated cells.

\section{Increase in number of RAD51 foci}

To evaluate a contribution of HR repair relative to total DNA double-strand break repair induced by chronic irradiation, we measured foci number and intensity for a key component of HR, RAD51. Normal human skin fibroblasts were exposed to $4.5 \mathrm{mGy} / \mathrm{min} \mathrm{X}$-ray radiation for up to $6 \mathrm{~h}$ and RAD51 foci were quantified as described in Methods. We observed increases in the number of RAD51 foci with time of exposure to X-ray radiation (Figure 3). Statistically significant changes were observed at $2 \mathrm{~h}$ of exposure and foci continued to accumulate up to $6 \mathrm{~h}$. This was in contrast to $\gamma \mathrm{H} 2 \mathrm{AX}$ foci whose number did not increase beyond $2 \mathrm{~h}$ of exposure.

\section{Increase in integral RAD51 fluorescence intensity}

Similar to $\gamma \mathrm{H} 2 \mathrm{AX}$ analyses, to better understand the kinetics of quantified RAD51 foci, we also measured integral fluorescence intensity of RAD51. The kinetics curve for integral RAD51 foci fluorescence intensity (Figure 4) mimicked the one obtained for RAD51 foci number (Figure 3), indicating that the lower rate of RAD51 foci accumulation between 2 and $6 \mathrm{~h}$, as in the case for $\gamma \mathrm{H} 2 \mathrm{AX}$ foci, was not due to overlapped or merged foci.

Shown in Figure 5 are representative microphotographs of $\gamma \mathrm{H} 2 \mathrm{AX}$ and RAD51 foci obtained for various radiation exposure times. They illustrate the findings that $\gamma \mathrm{H} 2 \mathrm{AX}$ foci accumulate faster, but plateau at around $2 \mathrm{~h}$ of exposure, in contrast to RAD51 foci that accumulate initially slower compared with $\gamma \mathrm{H} 2 \mathrm{AX}$ foci but do not plateau up to the latest time-point of $6 \mathrm{~h}$. 

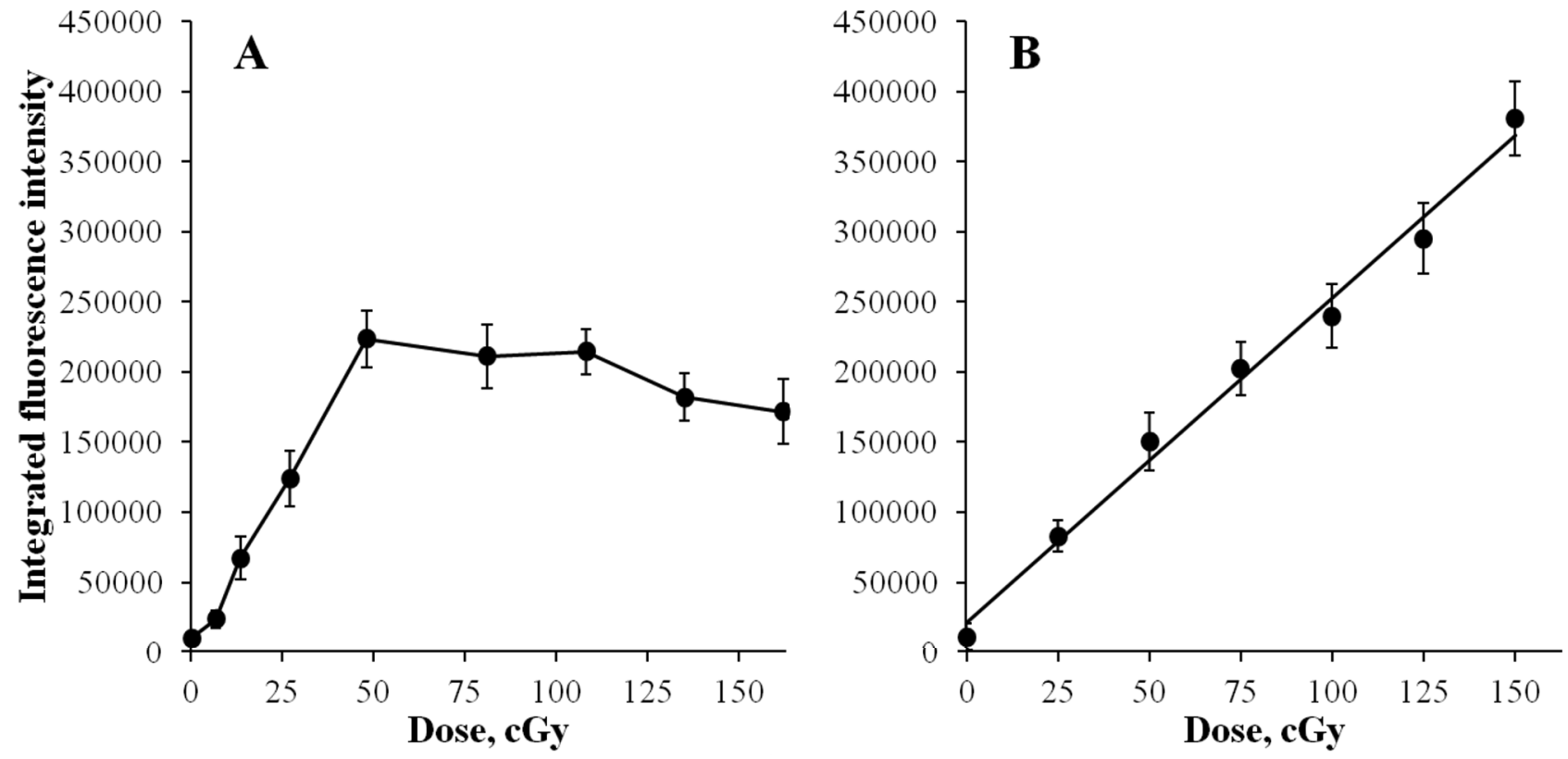

Figure 2: Changes in integral $\gamma \mathrm{H} 2 \mathrm{AX}$ fluorescence in diploid normal human fibroblasts during continuous exposure to $X$-ray radiation at a dose-rate of $4.5 \mathrm{mGy} / \mathrm{min} \mathrm{A}$. or $30 \mathrm{~min}$ after acute X-ray irradiation $\mathrm{B}$. $\gamma \mathrm{H} 2 \mathrm{AX}$ fluorescence was measured using immunofluorescence microscopy. Two hundred cells per data point were analyzed per experiment. Means calculated from three independent experiments \pm standard errors are shown.

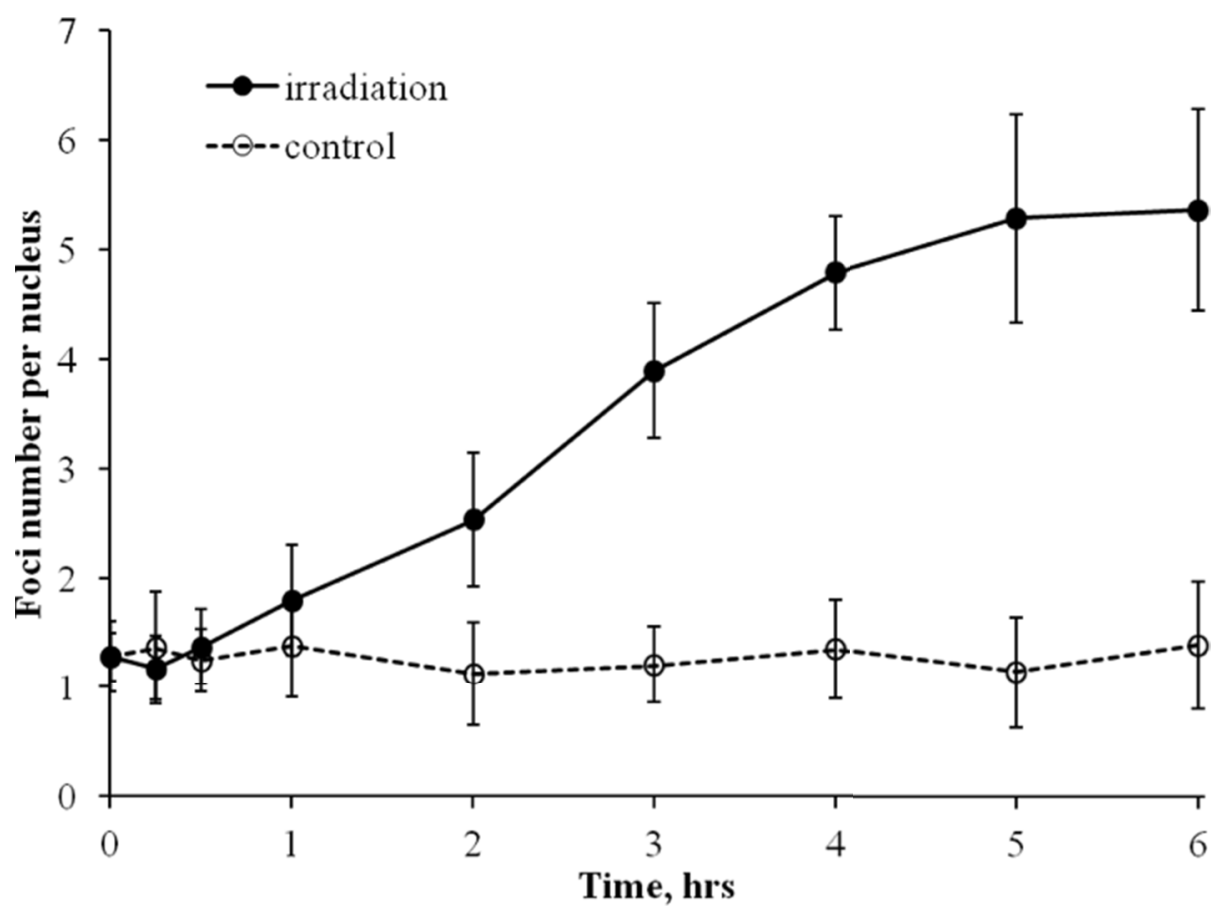

Figure 3: Formation of RAD51 foci in diploid normal human fibroblasts during continuous exposure to X-ray radiation at a dose-rate of $4.5 \mathrm{mGy} / \mathrm{min}$. RAD51 foci were quantified using immunofluorescence microscopy. Two hundred cells per data point were analyzed per experiment. Means calculated from three independent experiments \pm standard errors are shown. 


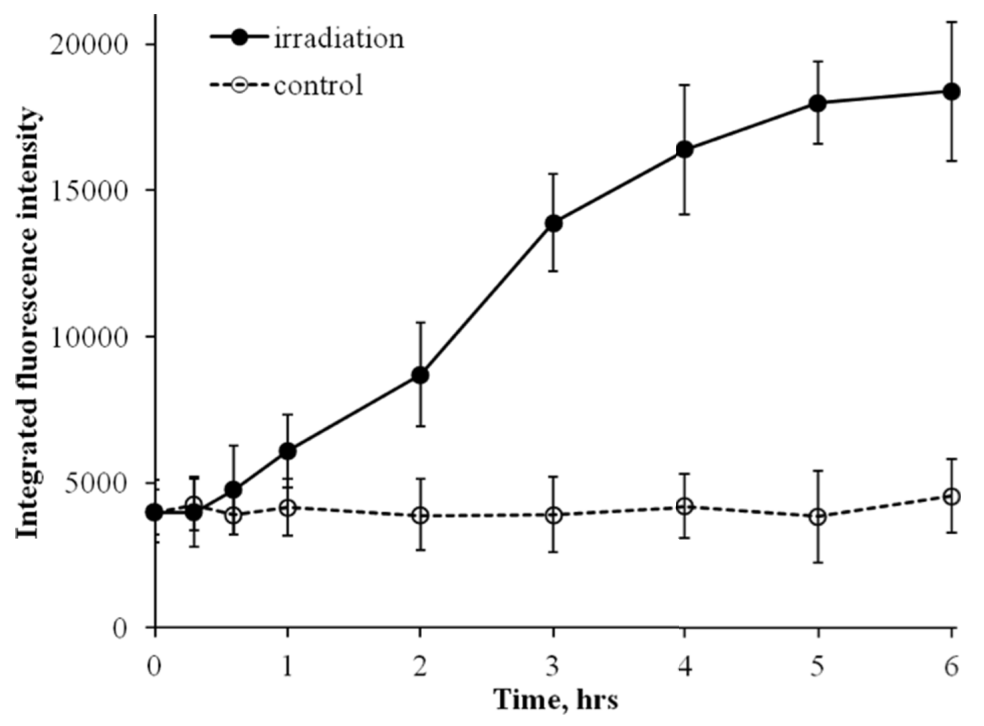

Figure 4: Changes in integral RAD51 fluorescence in diploid normal human fibroblasts during continuous exposure to X-ray radiation at a dose-rate of $\mathbf{4 . 5} \mathbf{~ m G y / m i n . ~ R A D 5 1 ~ f l u o r e s c e n c e ~ w a s ~ m e a s u r e d ~ u s i n g ~ i m m u n o f l u o r e s c e n c e ~ m i c r o s c o p y . ~}$ Two hundred cells per data point were analyzed per experiment. Means calculated from three independent experiments \pm standard errors are shown.

\section{Increase in RAD51 is not attributable to S/G2 cell cycle arrest}

One important difference between RAD51 and $\gamma \mathrm{H} 2 \mathrm{AX}$ foci, within the context of this study, is that the former foci form predominantly in S/G2 cells, whereas the latter form in cells in any phase of the cell cycle. Thus, it was reasonable to assume that the increase of RAD51 past $2 \mathrm{~h}$ exposure time, with no further increases in $\gamma \mathrm{H} 2 \mathrm{AX}$ within the same time frame, may be indicative of the $\mathrm{S} / \mathrm{G} 2$ cell cycle arrest, rather than enhanced HR repair pathway. To test this assumption we examined the distribution of cells with various RAD51 foci numbers (Figure 6). We found that by $2 \mathrm{~h}$ of radiation exposure the fraction of cells without RAD51 foci, typically representing G0/G1 cells, decreased to $\sim 65 \%$ from $\sim 80 \%$ in control un-irradiated cells. Further irradiation up to $6 \mathrm{~h}$ did not result in a further decrease in the fraction of cells without RAD51 foci, indicating that cell cycle distribution of cells did not change between 2 and $6 \mathrm{~h}$ of exposure.

\section{DISCUSSION}

Radiotherapy is a key treatment for cancer. However, exposure of normal cells to ionizing radiation is associated with known health risks, such as cancer. While molecular and cellular response to acute radiation exposure is well-studied, fewer studies have examined responses to continuous or chronic exposures. In this study, we sought to determine the effects of continuous exposure to ionizing radiation on DNA double-strand breaks and repair. Using normal human skin fibroblasts, we measured the effects of a continuous 6-h exposure using X-ray radiation at a dose rate of $4.5 \mathrm{mGy} / \mathrm{min}$ on DNA double-strand breaks. We used two markers to measure the effects: $\gamma \mathrm{H} 2 \mathrm{AX}$, which indicates a total number of DNA double-strand breaks, and RAD51, a marker of the slow, but error free HR repair process. We found that both the number and intensity of $\gamma \mathrm{H} 2 \mathrm{AX}$ and RAD51 foci increased over time; however, the kinetics of these increases differed markedly. While $\gamma \mathrm{H} 2 \mathrm{AX}$ foci increased linearly over the first $2 \mathrm{~h}$ of exposure, they plateaued thereafter. RAD51 foci, on the other hand, continued to increase throughout the 6-h irradiation experiment. In the following, we discuss these results and the hypothesis that these findings indicate an adaptive repair response to continuous radiation exposure that reduces the risk of long-term damage to the cell.

\section{Increase in $\gamma \mathrm{H} 2 \mathrm{AX}$ foci}

Our results indicate that kinetics of DNA doublestrand break formation upon continuous exposure to $\mathrm{X}$-ray radiation monitored in normal human fibroblasts using $\gamma \mathrm{H} 2 \mathrm{AX}$ foci consists of two components: i) linear accumulation with time (dose) of exposure, and ii) plateau. The first linear component observed between 0 and $2 \mathrm{~h}$ of irradiation reflects accumulation of DNA double-strand breaks and somewhat slower repair compared with the breaks produced by acute irradiation. As a result, the number of DNA double-strand breaks or $\gamma \mathrm{H} 2 \mathrm{AX}$ foci within the first $2 \mathrm{~h}$ of irradiation per cell per Gy was unexpectedly higher than that observed in human fibroblasts exposed to acute irradiation ( $\sim 50$ foci/ cell in this study compared with $\sim 36$ foci/cell in [25]). This observation, at first counter-intuitive, could be explained by a longer average life span of $\gamma \mathrm{H} 2 \mathrm{AX}$ foci 


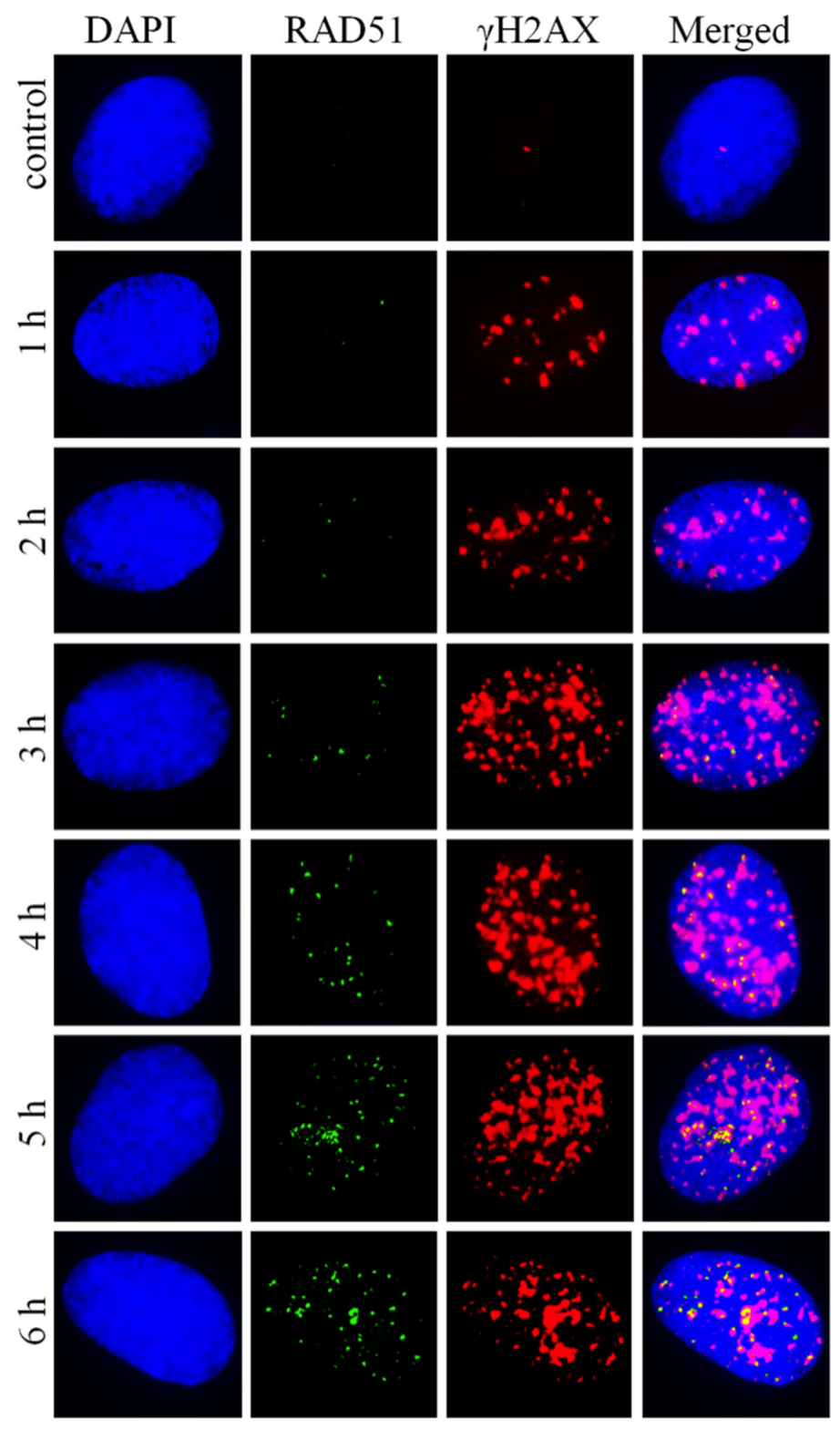

Figure 5: Representative microphotographs of RAD51 and $\gamma \mathrm{H2AX}$ foci formed in diploid normal human fibroblasts upon exposure to $\mathrm{X}$-ray radiation at a dose-rate of $4.5 \mathrm{mGy} / \mathrm{min}$.

upon chronic radiation exposure compared with acute irradiation, resulting in faster accumulation of foci. Indeed, depending on the complexity of the doublestrand break, repair time may vary between minutes and hours [5]. Besides, the number of $\gamma \mathrm{H} 2 \mathrm{AX}$ foci per Gy obtained in our study is consistent with the number of ATM foci co-localized with $\gamma \mathrm{H} 2 \mathrm{AX}$ foci in a study by Suzuki et al. [29].

\section{Increase in $\gamma \mathrm{H} 2 \mathrm{AX}$ intensity}

As the number of $\gamma \mathrm{H} 2 \mathrm{AX}$ foci accumulates with time/dose of exposure, newly formed foci can potentially overlap with the existing foci. In this case, discrimination of individual foci represents a significant technical challenge. Additionally, metabolic processing of damaged chromatin may lead to foci clustering within decondensed chromatin [30] or so called repair factories [31]. All these processes can result in underestimating foci number. The intensity of $\gamma \mathrm{H} 2 \mathrm{AX}$ foci, in these cases, would provide a more accurate evaluation of DNA double-strand break accumulation. As evident from Figure 2A showing the kinetics of $\gamma \mathrm{H} 2 \mathrm{AX}$ foci intensity, the lack of $\gamma \mathrm{H} 2 \mathrm{AX}$ foci accumulation beyond $2 \mathrm{~h}$ in our experiments was not caused by the process of foci overlapping and merging. Additionally, we show that our method of $\gamma \mathrm{H} 2 \mathrm{AX}$ foci quantification (Figure 1B) and 


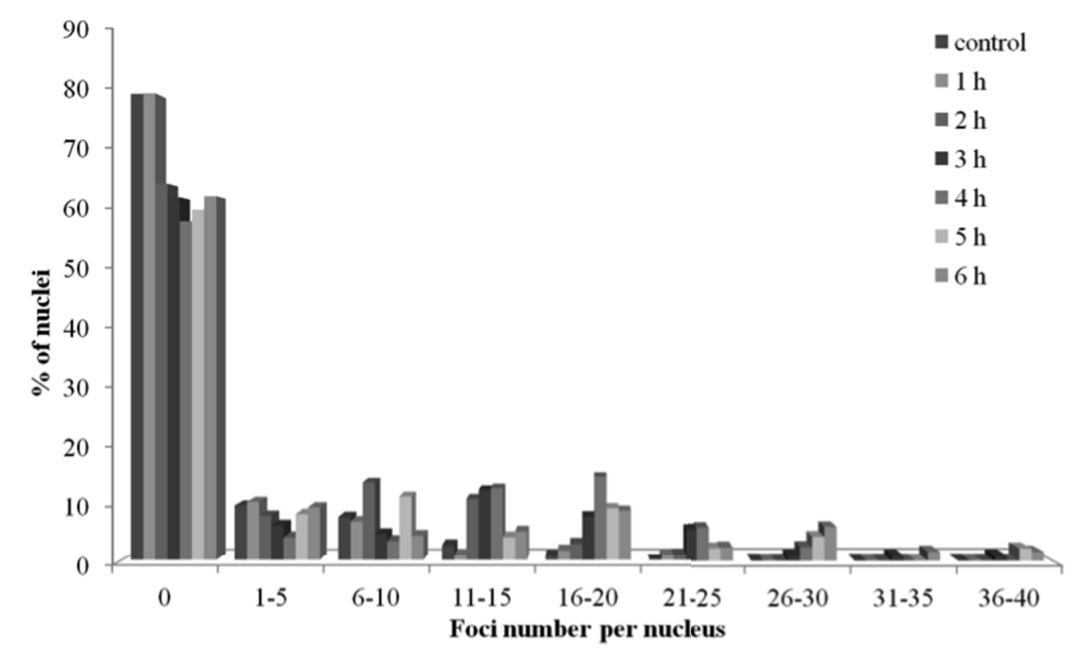

Figure 6: Distribution of diploid normal human fibroblasts with various numbers of RAD51 foci upon exposure to $\mathrm{X}$-ray radiation at a dose-rate of $4.5 \mathrm{mGy} / \mathrm{min}$ for indicated periods of time.

measuring total $\gamma \mathrm{H} 2 \mathrm{AX}$ fluorescence (Figure 2B) has a wide linear range of detection that exceeds substantially the plateau values, validating our continuous irradiation results. Thus, the observed kinetics of the $\gamma \mathrm{H} 2 \mathrm{AX}$ end-points is an accurate representation of DNA double-strand break formation and repair upon continuous X-ray irradiation.

\section{Increases in RAD51 foci and intensity}

When interpreting results of $\gamma \mathrm{H} 2 \mathrm{AX}$ measurements, specifically in terms of potential long-term biological outcomes, such as genetic instability and cancer risk, it is important to consider that the disappearance of a $\gamma \mathrm{H} 2 \mathrm{AX}$ focus technically means only a completion of ligation of two double-stranded DNA ends. This rejoining may be completed with substantial errors leading to gross cytogenetic abnormalities, such as dicentrics, rings, etc. The predominant pathway for DNA double-strand break repair, specifically at high dose-rate exposures, is NHEJ, which is prone to loss of genetic information. The loss could be very substantial in cases when overhangs on the ends of doublestrand breaks are not homologous (microhomologies) and may reach millions of nucleotides and lead to deletions [32]. It is, therefore, advisable in DNA repair studies, if estimates of potential biological consequences are to be made, to not only measure the rate and completion of rejoining of DNA double-strand breaks, such as those provided by $\gamma \mathrm{H} 2 \mathrm{AX}$ assays, but also to evaluate contribution of the HR repair pathway. The ratio of NHEJ to HR components was shown to be a very important prognostic factor in irradiated cell populations that correlates with the radiosensitivity of cells [33].

In our experiments, both the number and intensity of RAD51 foci, indicative of HR activity, increased within the entire irradiation time period of $6 \mathrm{~h}$ (Figures 3 and 4). This is in contrast to $\gamma \mathrm{H} 2 \mathrm{AX}$ data that showed increases only within the first $2 \mathrm{~h}$ of irradiation. The increases in RAD51 foci number and their intensity per cell were not caused by an accumulation of cells in S/G2 phases of the cell cycle, as evident from Figure 6. Instead, they should be attributed to an increased number of DNA double-strand breaks that are repaired by the HR pathway relative to the total number of DNA double-strand breaks. It should be noted that the enhancement of HR might be a result of higher rates of secondary double-strand breaks within collapsed replication forks. Overall, our data indicate that at some point during continuous radiation exposure, activation of the HR repair of DNA double-strand breaks is triggered in normal cells by as yet unknown mechanisms.

\section{Adaptive response hypothesis}

Firstly, the presence of a plateau in the kinetics curve of $\gamma \mathrm{H} 2 \mathrm{AX}$ foci/intensity, assuming they represent DNA double-strand breaks, can be considered as an activation of end rejoining or repair. Interestingly, similar results were obtained for low dose-rate irradiation in our recent study in immortalized Chinese hamster V79 fibroblasts [34], as well as for acute irradiations in earlier studies using indirect DNA damage end-points [35]. Inducible DNA repair was shown to be involved in such dose-responses [35]. Thus, the plateau observed in this study for $\gamma \mathrm{H} 2 \mathrm{AX} / \mathrm{DNA}$ double-strand breaks may also be thought of as an adaptation process typically observed after low doses of acute irradiation (<200 mGy).

Secondly, the qualitative changes in the way DNA double-strand breaks are repaired past $2 \mathrm{~h}$ of exposure, seen as an activation of the HR pathway, can further be considered through a prism of adaptive changes. Indeed, with the HR pathway being less prone to errors compared to the NHEJ repair pathway that may result in point mutations and gross chromosomal aberrations [36, 37], the observed activation of HR may alleviate potential long 
term detrimental outcomes of irradiation, such as genetic instability and cancer. In line with this, it was shown that TERT-immortalized human fibroblasts respond to low dose-rate irradiation $(0.3 \mathrm{mGy} / \mathrm{min})$ with lower yields of chromosomal abnormalities and cell death per unit dose compared with high dose-rate $(2000 \mathrm{mGy} / \mathrm{min})$ irradiation [38]. Similar results have been reported for animal studies [39-41]. Interestingly, activated HR repair of DNA doublestrand breaks enhances survival not only in normal, but also in tumor cells. Increased levels of RAD51 have been observed in tumor cells and were associated with better survival after radiotherapy treatments; thus, RAD51 can be considered as one of the targets to radiosensitize tumor cells [42-44].

In summary, our results provide an insight into the mechanisms of DNA double-strand break formation and repair upon continuous exposure to X-ray radiation in normal human cells. The demonstrated activation of DNA double-strand break repair and the found predominant role of the HR pathway in this repair may be utilized in various medical practices and help improve management of health risks associated with continuous exposure to ionizing radiation.

\section{MATERIALS AND METHODS}

\section{Fibroblast cultures}

All reagents were purchased from Sigma-Aldrich (USA) and cell culture plasticware was purchased from Corning-Costar (USA), unless otherwise stated. Experiments were carried out using primary human normal fibroblasts derived from skin biopsies from healthy volunteers (males, 50-52 years of age). After obtaining informed consent, $2 \times 2 \mathrm{~mm}$ skin biopsies were excised from the area behind the ear under local anesthesia with $2 \%$ lidocaine. The biopsy material was placed in Dulbecco's Modified Eagles Medium (DMEM) supplemented with 5\% Fetal Bovine Serum (FBS; Biological Industries, Israel), 1 g/L D-glucose, 100 U/mL penicillin and $100 \mathrm{U} / \mathrm{mL}$ streptomycin, and immediately transported to cell culture laboratory. Following the treatment with collagenase type II, cell suspensions were incubated for $14 \mathrm{~h}$ under $37^{\circ} \mathrm{C}$ and $5 \% \mathrm{CO}_{2}$ in high glucose (4.5 g/L) DMEM supplemented with 20\% FBS, 2 mmol/L L-glutamine (StemCell Technology, USA) and antibiotics. Cells were then detached using $0.05 \%$ trypsin in EDTA (StemCell Technology, USA) and seeded at $10^{4}$ cells $/ \mathrm{cm}^{2}$ in DMEM supplemented as in the previous step with the exception of lower FBS concentration (10\%). Fibroblasts were expanded by sub-culturing at 80-90\% confluency, with medium changed every 3 days. Cells were then detached, frozen and stored in liquid nitrogen in complete DMEM supplemented with 10\% DMSO. For experiments, cryovials with cells were quickly defrosted in $37^{\circ} \mathrm{C}$ water bath and complete DMEM was slowly added to cells to a total volume of $50 \mathrm{~mL}$. A small aliquot of cells was used to determine cell viability using Countess cell counter (Invitrogen, USA) according to the manufacturer instructions. For all experiments, viability was $\geq 92 \%$. Three days later, exponentially growing cells ( $\sim 70 \%$ confluency) were trypsinized and seeded onto coverslips (SPL Lifesciences, South Korea) placed inside $35 \mathrm{~mm}$ petri dishes. Next day cells attached to coverslips were exposed to X-ray radiation. Acutely irradiated cells were returned to a $\mathrm{CO}_{2}$ incubator for $30 \mathrm{~min}$ followed by a fixation.

\section{Irradiation}

For protracted irradiation, cells were exposed to $50 \mathrm{kV}$ X-rays at a dose rate of $4.5 \mathrm{mGy} / \mathrm{min}(0.4 \mathrm{~mA}$, $1.5 \mathrm{~mm} \mathrm{A1}$ filter) using RUB RUST-M1 X-irradiator (Russia). Throughout the irradiation, cells were maintained at $37^{\circ} \mathrm{C}$ using a heated stage with a thermo-regulator. Acute irradiation was carried out on ice using the same device and the dose rate was $400 \mathrm{mGy} / \mathrm{min}$.

\section{Foci detection and analysis}

Cells were fixed on coverslips in $4 \%$ paraformaldehyde in phosphate buffered saline (PBS, $\mathrm{pH}$ 7.4) for $20 \mathrm{~min}$ at room temperature followed by two rinses in PBS and permeabilization in $0.3 \%$ Triton-X100 (in PBS, pH 7.4) supplemented with $2 \%$ bovine serum albumin (BSA) to block non-specific antibody binding. Then, cells were incubated with primary mouse monoclonal antibody against $\gamma \mathrm{H} 2 \mathrm{AX}$ (05-636-I clone JBW301, Merck-Millipore, USA) and rabbit polyclonal antibody against RAD51 (ABE257, Merck-Millipore, USA) diluted in PBS (1:400 and $1: 200$, respectively) with $1 \% \mathrm{BSA}$ for $1 \mathrm{~h}$ at room temperature. Following several rinses with PBS, cells were incubated with a mix of secondary goat anti-mouse (Alexa Fluor 555 conjugated, dilution 1:1000) and goat anti-rabbit (Alexa Fluor 488 conjugated, dilution 1:600; both from Life Technologies, USA) diluted in PBS with $1 \%$ BSA for $1 \mathrm{~h}$ at room temperature. Coverslips were then rinsed several times with PBS and mounted on microscope slides with ProLong Gold medium (Life Technologies, USA) with DAPI for DNA counter-staining. Cells were viewed and imaged using Nikon Eclipse Ni-U microscope (Nikon, Japan) equipped with a high definition camera ProgRes MFcool (Jenoptik AG, Germany). Filter sets used were UV-2E/C (340-380 nm excitation and 435-485 $\mathrm{nm}$ emission), B-2E/C (465-495 nm excitation and 515-555 nm emission) and Y-2E/C (540-580 nm excitation and 600-660 nm emission). At least 200 cells per data point were imaged. Foci were enumerated using Focicounter (http://focicounter .sourceforge.net/). Integral foci fluorescence was measured using DARFI (https://github.com/varnivey/darfi).

\section{Statistical analysis}

Statistical and mathematical analyses of the data were conducted using the Statistica 8.0 software (StatSoft). 
Data points in Figures are mean values obtained from three independent experiments; error bars are standard errors. Statistical significance was tested using the Student $t$-test at $p<0.05$.

\section{ACKNOWLEDGMENTS AND FUNDING}

The studies were supported by the Russian Foundation for Basic Research grant \#12-04-01733-a and the Russian Scientific Foundation grant \#14-25-00166. The authors would like to thank Dr. Leslie C. Jellen of the University of Tennessee for her help with preparing and editing the manuscript and Diana Golubeva of McMaster University and Matthew Flegal of Canadian Nuclear Laboratories for proof reading the manuscript.

\section{CONFLICTS OF INTEREST}

The authors declare no conflict of interest.

\section{REFERENCES}

1. Goodarzi AA, Jeggo P, Lobrich M. The influence of heterochromatin on DNA double strand break repair: Getting the strong, silent type to relax. DNA Repair (Amst). 2010; 9:1273-1282.

2. Shibata A, Jeggo PA. DNA double-strand break repair in a cellular context. Clin Oncol (R Coll Radiol). 2014; 26:243-249.

3. Sai S, Wakai T, Vares G, Yamada S, Kamijo T, Kamada T, Shirai T. Combination of carbon ion beam and gemcitabine causes irreparable DNA damage and death of radioresistant pancreatic cancer stem-like cells in vitro and in vivo. Oncotarget. 2015; 6:5517-5535.

4. Rothkamm K, Lobrich M. Evidence for a lack of DNA double-strand break repair in human cells exposed to very low x-ray doses. Proc Natl Acad Sci U S A. 2003; 100:5057-5062.

5. Neumaier T, Swenson J, Pham C, Polyzos A, Lo AT, Yang P, Dyball J, Asaithamby A, Chen DJ, Bissell MJ, Thalhammer S, Costes SV. Evidence for formation of DNA repair centers and dose-response nonlinearity in human cells. Proc Natl Acad Sci U S A. 2012; 109:443-448.

6. Thompson LH. Recognition, signaling, and repair of DNA double-strand breaks produced by ionizing radiation in mammalian cells: the molecular choreography. Mutat Res. 2012; 751:158-246.

7. Halazonetis TD, Gorgoulis VG, Bartek J. An oncogeneinduced DNA damage model for cancer development. Science. 2008; 319:1352-1355.

8. Aparicio T, Baer R, Gautier J. DNA double-strand break repair pathway choice and cancer. DNA Repair (Amst). 2014; 19:169-175.
9. Terasawa M, Shinohara A, Shinohara M. Double-strand break repair-adox: Restoration of suppressed double-strand break repair during mitosis induces genomic instability. Cancer science. 2014; 105:1519-1525.

10. Mao Z, Bozzella M, Seluanov A, Gorbunova V. Comparison of nonhomologous end joining and homologous recombination in human cells. DNA Repair (Amst). 2008; 7:1765-1771.

11. Mladenov E, Iliakis G. Induction and repair of DNA double strand breaks: the increasing spectrum of non-homologous end joining pathways. Mutat Res. 2011; 711:61-72.

12. Vignard J, Mirey G, Salles B. Ionizing-radiation induced DNA double-strand breaks: a direct and indirect lighting up. Radiotherapy and oncology : journal of the European Society for Therapeutic Radiology and Oncology. 2013; 108:362-369.

13. Petermann E, Orta ML, Issaeva N, Schultz N, Helleday T. Hydroxyurea-stalled replication forks become progressively inactivated and require two different RAD51-mediated pathways for restart and repair. Molecular cell. 2010; 37:492-502.

14. Tomita M, Morohoshi F, Matsumoto Y, Otsuka K, Sakai K. Role of DNA double-strand break repair genes in cell proliferation under low dose-rate irradiation conditions. Journal of radiation research. 2008; 49:557-564.

15. Sugihara T, Murano H, Tanaka K. Increased gammaH2A.X intensity in response to chronic medium-dose-rate gamma-ray irradiation. PloS one. 2012; 7:e45320.

16. Osipov AN, Buleeva G, Arkhangelskaya E, Klokov D. In vivo gamma-irradiation low dose threshold for suppression of DNA double strand breaks below the spontaneous level in mouse blood and spleen cells. Mutat Res. 2013; 756:141-145.

17. Collis SJ, Schwaninger JM, Ntambi AJ, Keller TW, Nelson WG, Dillehay LE, Deweese TL. Evasion of early cellular response mechanisms following low level radiation-induced DNA damage. J Biol Chem. 2004; 279:49624-49632.

18. Sokolnikov M, Preston D, Gilbert E, Schonfeld S, Koshurnikova N. Radiation effects on mortality from solid cancers other than lung, liver, and bone cancer in the mayak worker cohort: 1948-2008. PloS one. 2015; 10:e0117784.

19. Nenoi M, Wang B, Vares G. In vivo radioadaptive response: a review of studies relevant to radiation-induced cancer risk. Human \& experimental toxicology. 2015; 34:272-283.

20. Shore RE. Radiation impacts on human health: certain, fuzzy, and unknown. Health physics. 2014; 106:196-205.

21. Paull TT, Rogakou EP, Yamazaki V, Kirchgessner CU, Gellert M, Bonner WM. A critical role for histone H2AX in recruitment of repair factors to nuclear foci after DNA damage. Current biology: CB. 2000; 10:886-895.

22. Sharma A, Singh K, Almasan A. Histone H2AX phosphorylation: a marker for DNA damage. Methods Mol Biol. 2012; 920:613-626. 
23. Grudzenski S, Raths A, Conrad S, Rube CE, Lobrich M. Inducible response required for repair of low-dose radiation damage in human fibroblasts. Proc Natl Acad Sci U S A. 2010; 107:14205-14210.

24. Ivashkevich AN, Martin OA, Smith AJ, Redon CE, Bonner WM, Martin RF, Lobachevsky PN. gammaH2AX foci as a measure of DNA damage: a computational approach to automatic analysis. Mutation research. 2011; 711:49-60.

25. Lobrich M, Shibata A, Beucher A, Fisher A, Ensminger M, Goodarzi AA, Barton O, Jeggo PA. gammaH2AX foci analysis for monitoring DNA double-strand break repair: strengths, limitations and optimization. Cell Cycle. 2010; 9:662-669.

26. Graeser M, McCarthy A, Lord CJ, Savage K, Hills M, Salter J, Orr N, Parton M, Smith IE, Reis-Filho JS, Dowsett M, Ashworth A, Turner NC. A marker of homologous recombination predicts pathologic complete response to neoadjuvant chemotherapy in primary breast cancer. Clinical cancer research : an official journal of the American Association for Cancer Research. 2010; 16:6159-6168.

27. Daley JM, Kwon Y, Niu H, Sung P. Investigations of homologous recombination pathways and their regulation. The Yale journal of biology and medicine. 2013; 86:453-461.

28. Rothkamm K, Barnard S, Moquet J, Ellender M, Rana Z, Burdak-Rothkamm S. DNA damage foci: Meaning and significance. Environ Mol Mutagen. 2015; 56:491-504.

29. Suzuki K, Okada H, Yamauchi M, Oka Y, Kodama S, Watanabe M. Qualitative and quantitative analysis of phosphorylated ATM foci induced by low-dose ionizing radiation. Radiat Res. 2006; 165:499-504.

30. Falk M, Lukasova E, Kozubek S. Higher-order chromatin structure in DSB induction, repair and misrepair. Mutat Res. 2010; 704:88-100.

31. Scherthan H, Hieber L, Braselmann H, Meineke V, Zitzelsberger H. Accumulation of DSBs in gamma-H2AX domains fuel chromosomal aberrations. Biochem Biophys Res Commun. 2008; 371:694-697.

32. Sankaranarayanan K, Taleei R, Rahmanian S, Nikjoo H. Ionizing radiation and genetic risks. XVII. Formation mechanisms underlying naturally occurring DNA deletions in the human genome and their potential relevance for bridging the gap between induced DNA double-strand breaks and deletions in irradiated germ cells. Mutat Res. 2013; 753:114-130.

33. Lim YC, Roberts TL, Day BW, Stringer BW, Kozlov S, Fazry S, Bruce ZC, Ensbey KS, Walker DG, Boyd AW, Lavin MF. Increased sensitivity to ionizing radiation by targeting the homologous recombination pathway in glioma initiating cells. Molecular oncology. 2014; 8:1603-1615.
34. Kotenko KV, Bushmanov AY, Ozerov IV, Guryev DV, Anchishkina NA, Smetanina NM, Arkhangelskaya EY, Vorobyeva NY, Osipov AN. Changes in the number of double-strand DNA breaks in Chinese hamster V79 cells exposed to gamma-radiation with different dose rates. International journal of molecular sciences. 2013; 14:13719-13726.

35. Zaichkina SI, Rozanova OM, Aptikaeva GF, Achmadieva A, Klokov DY. Low doses of gamma-radiation induce nonlinear dose responses in Mammalian and plant cells. Nonlinearity Biol Toxicol Med. 2004; 2:213-221.

36. Sasaki MS, Takata M, Sonoda E, Tachibana A, Takeda S. Recombination repair pathway in the maintenance of chromosomal integrity against DNA interstrand crosslinks. Cytogenetic and genome research. 2004; 104:28-34.

37. Kakarougkas A, Jeggo PA. DNA DSB repair pathway choice: an orchestrated handover mechanism. The British journal of radiology. 2014; 87:20130685.

38. Nakamura H, Fukami H, Hayashi Y, Tachibana A, Nakatsugawa S, Hamaguchi M, Ishizaki K. Cytotoxic and mutagenic effects of chronic low-dose-rate irradiation on TERT-immortalized human cells. Radiat Res. 2005; 163:283-288.

39. Osipov AN, Klokov DY, Elakov AL, Rozanova OM, Zaichkina SI, Aptikaeva GF, Akhmadieva A. Comparison in vivo Study of Genotoxic Action of High- Versus Very Low Dose-Rate gamma-Irradiation. Nonlinearity Biol Toxicol Med. 2004; 2:223-232.

40. Tanaka K, Kohda A, Toyokawa T, Ichinohe K, Oghiso Y. Chromosome aberration frequencies and chromosome instability in mice after long-term exposure to low-dose-rate gamma-irradiation. Mutat Res. 2008; 657:19-25.

41. Tanaka K, Kohda A, Satoh K, Toyokawa T, Ichinohe K, Ohtaki M, Oghiso Y. Dose-rate effectiveness for unstabletype chromosome aberrations detected in mice after continuous irradiation with low-dose-rate gamma rays. Radiat Res. 2009; 171:290-301.

42. Wiegmans AP, Al-Ejeh F, Chee N, Yap PY, Gorski JJ, Da Silva L, Bolderson E, Chenevix-Trench G, Anderson R, Simpson PT, Lakhani SR, Khanna KK. Rad1 supports triple negative breast cancer metastasis. Oncotarget. 2014; 5:3261-3272.

43. Magin S, Papaioannou M, Saha J, Staudt C, Iliakis GE. Inhibition of homologous recombination and promotion of mutagenic repair of DNA double-strand breaks underpins arabinoside-nucleoside analog-radiosensitization. Mol Cancer Ther. 2015; 14:1424-33.

44. Ward A, Khanna KK, Wiegmans AP. Targeting homologous recombination, new pre-clinical and clinical therapeutic combinations inhibiting RAD51. Cancer treatment reviews. 2015; 41:35-45. 